\title{
Aa. Vv., La question du baroque, «CEuvres et critiques , XXXII, 2
}

\section{Laura Rescia}

\section{(2) OpenEdition}

1 Journals

\section{Edizione digitale}

URL: http://journals.openedition.org/studifrancesi/8232

DOI: 10.4000/studifrancesi.8232

ISSN: 2421-5856

\section{Editore}

Rosenberg \& Sellier

\section{Edizione cartacea}

Data di pubblicazione: 1 mai 2009

Paginazione: 162-163

ISSN: 0039-2944

\section{Notizia bibliografica digitale}

Laura Rescia, «Aa. VV., La question du baroque, «EFuvres et critiques, XXXII, 2», Studi Francesi [Online],

157 (LIII | I) | 2009, online dal 30 novembre 2015, consultato il 13 janvier 2021. URL: http://

journals.openedition.org/studifrancesi/8232 ; DOI: https://doi.org/10.4000/studifrancesi.8232

Questo documento è stato generato automaticamente il 13 janvier 2021.

\section{(c) (i) $\odot$}

Studi Francesi è distribuita con Licenza Creative Commons Attribuzione - Non commerciale - Non opere derivate 4.0 Internazionale. 


\title{
Aa. Vv., La question du baroque, «EEuvres et critiques, XXXII, 2
}

\author{
Laura Rescia
}

\section{NOTIZIA}

La question du baroque, «CEuvres et critiques, XXXII, 2, 2007, pp. 203.

1 Questo numero tematico della rivista Euvres et critiques, coordinato da D. Scholl, si propone di ripensare il concetto di barocco a più di sessant'anni dai primi scritti di Jean Rousset e dai primi timidi utilizzi di tale categoria storico-estetica da parte della critica letteraria: esso ospita articoli importanti per verificare lo stato dell'arte sull'utilizzo del barocco letterario, che propongono interrogativi e soluzioni talvolta anche distanti o divergenti.

2 L'articolo di J.C. vUILLEMIN (Baroque: le mot et la chose, pp. 13-21) analizza la polisemia del termine, per postulare la necessità di una riflessione critica sulle categorie interpretative dell'oggetto letterario e culturale, necessariamente influenzate dall'osservatore. Il barocco è da intendersi, secondo l'A., quale strumento euristico meno significativo del XVII secolo quanto della modernità che si interroga sul Seicento. Riferendosi a Foucault e al suo discorso sulla connessione tra saperi e poteri, l'A. ripercorre l'emergenza del termine, sottolineando come la sua nascita, eccentrica rispetto ai confini della terra di Francia, abbia influito sulla sua esclusione o marginalizzazione da parte della critica francese. Percepito come termine reazionario, il barocco avrebbe risentito dello stigma ideologico applicato dai maîtres à penser della laicità dell'istruzione pubblica. L'A. propone dunque di rivisitare il barocco come rappresentante dello sguardo della modernità che scopre la scienza, «l'expression d'une certaine manière de concevoir le monde», proponendone altresì una nuova periodizzazione (1543-1704), corrispondente al periodo intercorso tra Copernico e Newton. 
3 V. KAPP (Le concept du baroque face aux doctrines oratoires du XVII siècle en Europe, pp. 23-36) esamina l'apporto del rinnovamento degli studi retorici sulla visione del Seicento francese, analizzando il discorso critico sulla «retorica barocca». Analizzando i dibattiti coevi sulle categorie del naturale, le querelles sull'ornato, e verificando l'applicazione delle categorie di asianesimo e atticismo, riportate in auge ai nostri giorni grazie a $\mathrm{M}$. Fumaroli, si disvela tutta la complessità del discorso del Seicento e sul Seicento, tale da impedire l'utilizzo di facili dicotomie. L'A. sostiene l'impossibilità di una perfetta sovrapposizione tra le poetiche barocche e altre categorie filosofiche, religiose e sociali: così come non si rivela esatto intenderlo come espressione della teologia gesuita, $\mathrm{e}$ connotare il contraltare classico come giansenista, non è possibile attribuire al discorso cartesiano l'etichetta di atticismo tout court.

C. RIZzA (Les études sur le baroque dans la revue «Studi Francesi», pp. 37-46) ricorda il percorso degli studi sul barocco pubblicati dalla rivista, a partire da Franco Simone e dal suo sforzo per modificare lo schema storiografico classico, emersi nei suoi articoli del biennio 1953-1954. Accogliendo i successivi contributi di M. Raymond, V.-L. Tapié, J. Rousset, O. de Morgues, la rivista diventava il punto di riferimento di tutta una generazione di studiosi, a cui si deve una nouvelle vague di riscoperte e riletture. Grazie anche alla prospettiva comparatistica, si andava definendo l'influenza dell'italianismo sulle poetiche francesi barocche. Una lunga serie di studi affrontava dunque la novella e il romanzo dell'età barocca, contribuendo alla riscoperta di minores come J.P. Camus, ma altresì rivalutando la lunga stagione teatrale del primo trentennio del secolo, nonché miti e tematiche elettivi dell'epoca. Grazie ai contributi di studiosi del calibro di D. Dalla Valle, M. Guglielminetti e C. Rizza stessa, le pagine della rivista anticipavano i contenuti di studi successivi e di volumi interamente dedicati al concetto di barocco.

D. Scholl (Baroque, arabesque, grotesque, pp. 45-80), dedica la sua riflessione alla compresenza delle tre categorie, interrogandosi sul valore euristico delle stesse, nelle opere letterarie come nella critica secentesca. In particolare, l'A. evidenzia l'interesse di utilizzare termini coevi che, a differenza del barocco, fossero già stati utilizzati per identificare un preciso sistema estetico e poetico: così, il "grottesco" di Montaigne e di Lomazzo verrà adottato in epoche successive, con connotazioni diverse, e stessa sorte varrà per l'arabesco. Attraverso un percorso à rebours, che da Gautier si sposta verso Saint Amant, l'A. propone la riabilitazione di queste categorie. F. Assaf (Francion: écriture moderne, écriture baroque pp. 81-108), dopo aver evocato le categorie descrittive di $\mathrm{H}$. Wölfflin, E. D'Ors, J. Rousset, D. Souiller, si concentra sulla tassonomia dell'immaginario proposta da Gilbert Durand, e sugli sviluppi della riflessione di J.-J. Wunenburger, utilizzando la dicotomia diurno/notturno e il concetto di disseminazione, nel loro rapporto con la modernità, per constatarne la presenza nella tessitura narrativa del Francion.

6 Con il suo contributo $\mathrm{Du}$ théâtre au Théâtre du monde: fragmentation et bigarrure (pp. 109-120) A. SURGERS arricchisce il dibattito con l'apporto di elementi di storia del teatro, indagando l'organizzazione del teatro barocco, e utilizzando il termine di polisemia per indicare la moltiplicazione dei punti di vista e la giustapposizione di frammenti iconografici sulla scena barocca, comparabile, nella sua organizzazione spaziale, all'emblematica. La riflessione dell'A. apre nuove ipotesi sulla ricezione dello spettacolo tra fine XVI e prima metà del XVII secolo.

7 Anche M. BRUNEL affronta il genere teatrale, ma dal punto di vista del testo letterario ne L'évolution de la pratique des stances théâtrales: un chemin de traverse du baroque vers le 
classicisme (pp. 121-134), indagando la funzione drammaturgica delle stanze nella tragedia e nella commedia dal 1630 al 1660, per poi constatarne la diminuita frequenza con l'affermarsi delle poetiche classiche, e la contemporanea condanna a livello teorico.

8 Gli ultimi quattro articoli declinano il barocco con i concetti di moderno e postmoderno: segnaliamo in particolare il contributo di R. ZAISER Le pli: Deleuze et le baroque (pp. 155-170), che propone una nuova e storicizzata applicazione del concetto di "piega» del filosofo francese che, a partire da Leibniz, individuava tale metafora per indagare una categoria dello spirito e le sue diverse produzioni. 